\title{
Geometric Parameter Analysis of Ruptured and Unruptured Aneurysms in Patients with Symmetric Bilateral Intracranial Aneurysms: A Multicenter CT Angiography Study
}

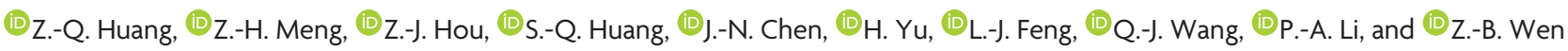

\begin{abstract}
BACKGROUND AND PURPOSE: Previous studies of geometric and morphologic parameters of intracranial aneurysms have been conducted to determine rupture risk, which remains incompletely defined due to patient-specific risk factors, such as sex, hypertension, and age. To this end, we compared characteristics of ruptured and unruptured aneurysms in the same patients with symmetric bilateral intracranial aneurysms.
\end{abstract}

MATERIALS AND METHODS: Between January 2008 and March 2014, 2361 patients with 2674 aneurysms were diagnosed by CT angiography or surgical findings at 4 medical centers. Geometric and morphologic parameters examined for symmetric bilateral intracranial aneurysms comprised aneurysm wall regularity, size, neck width, aspect ratio, size ratio, neck-to-parent artery ratio, and area ratio. Univariate and multivariate statistical analyses were performed to determine independent risk factors for rupture.

RESULTS: Sixty-three patients (48 women, 15 men; mean age, $62.5 \pm 9.8$ years) with symmetric bilateral aneurysms were eligible for the study and were included. The most frequent aneurysm location was the posterior communicating artery. Univariate analysis disclosed that aneurysm size, aspect ratio, size ratio, area ratio, and irregular wall differed between patients with ruptured and unruptured aneurysms. Multivariate analysis indicated that aspect ratio of $\geq 1.6$ (adjusted OR, 9.521; $95 \% \mathrm{Cl}, 2.182-41.535$ ), area ratio of $\geq 1.5$ (adjusted OR, $4.089 ; 95 \%$ $\mathrm{Cl}, 1.247-13.406$ ), and irregular shape (adjusted OR, 10.443; 95\% Cl 3.394-32.135) were significant predictive factors for aneurysm rupture after adjustment for aneurysm size.

CONCLUSIONS: An aspect ratio of $\geq 1.6$, area ratio of $\geq 1.5$, and irregular wall are associated with aneurysm rupture independent of aneurysm size and patient characteristics. These characteristics alone can help in distinguishing ruptured bilateral intracranial aneurysms from unruptured ones.

ABBREVIATIONS: $A_{2}=$ area of parent artery within the neck; $A_{1}=$ aneurysm area; $A R=$ aspect ratio; $S R=$ size ratio

$\mathbf{U}^{n}$

nruptured intracranial aneurysms are common lesions with a prevalence of $3 \%-7 \% .{ }^{1,2}$ Aneurysm rupture is the primary cause of subarachnoid hemorrhage, leading to high morbidity and mortality. Meanwhile, prophylactic treatment of unruptured

Received October 29, 2015; accepted after revision January 28, 2016.

From the Medical Image Center (Z.-Q.H., H.Y., L.-J.F., Z.-B.W.) and Department of Neurosurgery (Q.-J.W.), Zhujiang Hospital, Southern Medical University, Guangzhou, Guangdong Province, China; Medical Image Center (Z.-Q.H., Z.-H.M., J.-N.C.) and Department of Neurosurgery (P.-A.L.), Yuebei People's Hospital, Shantou University Medical College, Shantou, Guangdong Province, China; Department of Radiology (Z.-J.H.), The Second Affiliated Hospital of Guangzhou Medical University, Guangzhou, Guangdong Province, China; and Department of Radiology (S.-Q.H.), Sun Yat-Sen Memorial Hospital, Sun Yat-Sen University, Guangzhou, Guangdong Province, China.

This work was supported by the Shaoguan Science and Technology department (grant No. 2013 CX/K200).

Please address correspondence to Z.-B. Wen, MD, Image Diagnosis Center, Zhujiang Hospital, 253, Industrial Road, Haizhu District, Guangzhou, Guangdong Province, China; e-mail: zhibowen@163.com

http://dx.doi.org/10.3174/ajnr.A4764 intracranial aneurysms is also associated with risks. ${ }^{3,4}$ Therefore, identification of the risk factors for aneurysm rupture is essential for both risk assessment and treatment.

Previous research on geometric parameters, including aspect ratio (AR), size ratio (SR), and aneurysm flow angles, has shown their association with aneurysm rupture. ${ }^{5-7}$ However, conclusions are confounded by patient-specific characteristics, such as hypertension, age, and history of subarachnoid hemorrhage from another aneurysm which, along with geographic region, have been identified as risk factors for aneurysm rupture. ${ }^{8-10}$ Hence, aneurysm-related factors need to be analyzed by comparing the aneurysm characteristics of ruptured and unruptured aneurysms in the same individual to identify risk factors in a case-control design. We conducted a multicenter, retrospective cohort study of intracranial aneurysms in the Chinese population. The objectives of the article were to elucidate the morphologic and geometric parameters that discriminate intracranial aneurysm rupture status in the same patient with symmetric bilateral intracranial aneurysms. 

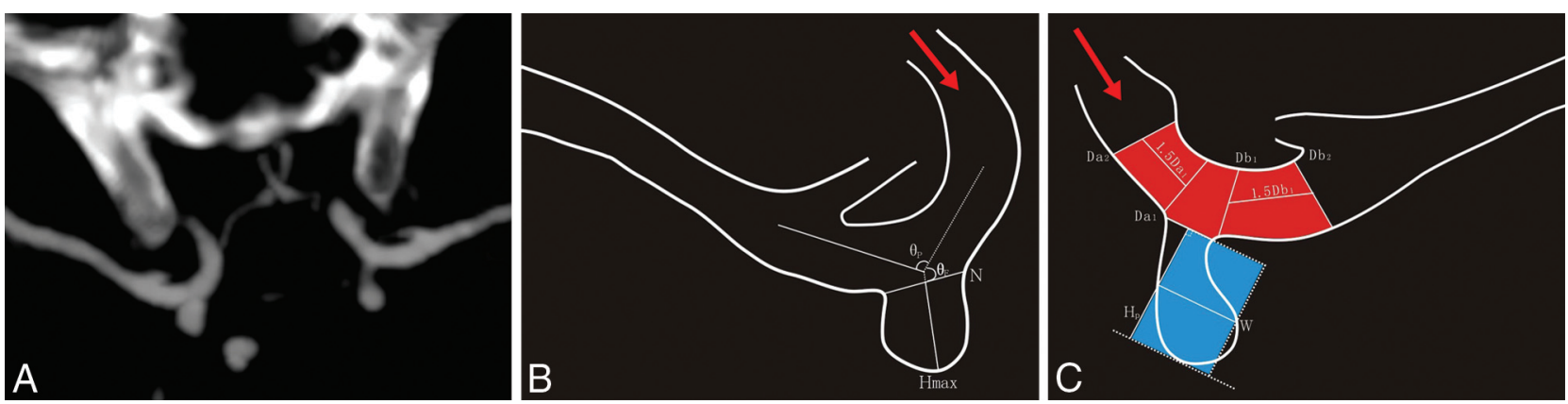

FIG 1. Methodology of morphologic and geometric parameter measurements. A, CT angiography shows maximum intensity projection with a $10-\mathrm{mm}$ section thickness, under $\times 4$ magnification and a standardized window setting, of symmetric bilateral intracranial aneurysms at the internal carotid artery. $B$, The angle maximum aneurysm height (Hmax) and neck width measurements are schematically shown. $C$, Area ratio measurements. The area ratio was defined as the area of the aneurysm to the parent artery in the neck plane. The area of the aneurysm (area with blue) is $\pi \times \mathrm{Hp} \times \mathrm{W}$, and the area of the parent artery within the neck (area with red) is $\pi \times \mathrm{Dv} \times \mathrm{N}$. The red arrow indicates blood flow direction.

\section{MATERIALS AND METHODS \\ Patient Selection and Data Collection}

A retrospective analysis was performed in patients diagnosed with intracranial aneurysms from January 2008 to March 2014 who underwent CT angiography with at least 64 sections at 1 of our 4 affiliated hospitals. At each participating center, the institutional review board approved this cohort study. The requirement for informed consent was waived because no diagnostic tests other than routine clinical imaging were used in this study. Additionally, we did not conduct research outside our country of residence.

Patient exclusion criteria were the following: 1) fusiform, traumatic, or mycotic aneurysms; 2) insufficient image quality to evaluate aneurysm geometry and morphology and poorly defined wide-neck aneurysms; 3 ) inability to identify the location of the ruptured aneurysm on the basis of the pattern of hemorrhage on CT or neurosurgical findings; and 4) an intracranial aneurysm related to arteriovenous malformation.

\section{Definition and Measurement of Morphologic and Geometric Parameters}

For each patient with SAH, noncontrast CT and CTA images were evaluated on the workstation that came with the CT scanner for morphologic and geometric variables of aneurysms. Patients were routinely checked at each hospital every day for treatment planning of both ruptured and unruptured aneurysms. CTA was performed with an FOV of $160 \mathrm{~mm}$ and a section thickness of 0.5 or $0.625 \mathrm{~mm}$ reconstructed at 0.5 or $0.625 \mathrm{~mm}$, resulting in a voxel size of $0.3 \times 0.3 \times 0.5$ (or 0.625 ) $\mathrm{mm}$. Noncontrast head CT images and neurosurgical findings were reviewed by a neuroradiologist (Z.-B.W., with 25 years of working experience in central nervous system vascular imaging), who was blinded to aneurysm geometry and morphology, to identify the location of the ruptured aneurysm in each patient.

Two neuroradiologists (Z.-Q.H and Z.-H.M, with 5 and 23 years of working experience in central nervous system vascular imaging, respectively) independently obtained measurements, and the average value was used for subsequent statistical analyses. ${ }^{11,12}$ If an aneurysm was detected, the 2 neuroradiologists evaluated several morphologic characteristics: 1) maximum aneurysm height (Fig 1), defined as the maximum distance from the neck center to the dome of the aneurysm; 2) maximal perpendicular height
$(\mathrm{Hp})$, defined as the largest perpendicular distance from the neck plane to the dome of the aneurysm; 3 ) aneurysm width (W) and neck width $(\mathrm{N})$, defined as the longest diameter of the aneurysm and its neck perpendicular to the Hp; 4) vessel diameter (Dv), already defined in the literature; and 5) flow angle and parentdaughter angle, as previously defined by Lin et al. ${ }^{6,13}$

We calculated the following secondary geometric indices: 1) aspect ratio (the ratio of maximum aneurysm height to $\mathrm{N}$ ); 2) size ratio (the ratio of maximum aneurysm height to the Dv); 3 ) neckto-parent-artery ratio (the ratio of $\mathrm{N}$ to $\mathrm{Dv}$ ); and 4) area ratio (the ratio of the area of the aneurysm to the parent artery in the neck plane). Therefore, the area of the aneurysm $\left(\mathrm{A}_{1}\right)$ is $\pi \times \mathrm{Hp} \times \mathrm{W}$, and the area of parent artery within neck $\left(\mathrm{A}_{2}\right)$ is $\pi \times \mathrm{Dv} \times \mathrm{N}$.

All measurements were performed on a workstation with an electronic caliper under $\times 4$ magnification, and maximum-intensity-projection images with 10 -mm section thickness and a standardized window setting (window level and window width equal to the Hounsfield unit within the aneurysm) were used. Measurements of morphologic and geometric parameters were performed on a $0.1-\mathrm{mm}$ or $0.1^{\circ}$ scale; secondary geometric indices were calculated on a 0.001-point scale. The maximum measurement of W or maximum aneurysm height was defined as the aneurysm size. Aneurysm shape was categorized into "spheric" (defined as an aneurysm ratio of $\mathrm{Hp}$ to $\mathrm{W}$ or $\mathrm{W}$ to $\mathrm{Hp}$ of $\geq 80 \%$ ), or "nonspheric"; the aneurysm wall was categorized as smooth (regular pouch without protrusions) or irregular (when blebs, lobes, or protrusions were present). Flow into the aneurysm was considered straight flow when the inflow angle was greater than the main branching angle; otherwise, it was considered as curved flow. If the inflow angle and the main branching angle showed $<10^{\circ}$ difference, flow was considered equivalent.

\section{Statistical Analysis}

SPSS 17.0 (IBM, Armonk, New York) and Excel 2007 (Microsoft, Redmond, Washington) were used for all statistical analyses. Quantitative data of each geometric parameter were presented in the form of mean $\pm \mathrm{SD}(\overline{\mathrm{x}} \pm \mathrm{s})$, calculated for the ruptured and unruptured groups, and were analyzed with a paired $t$ test. For further analysis, the cutoff value was calculated by the receiver operating characteristic. The criteria of cut-point selection are 
Table 1: Geometric parameters of ruptured and unruptured aneurysms $(\bar{x} \pm s)$

\begin{tabular}{lccc}
\hline Geometric Parameters & $\begin{array}{c}\text { Unruptured } \\
(\boldsymbol{n}=63)\end{array}$ & $\begin{array}{c}\text { Ruptured } \\
(\boldsymbol{n}=63)\end{array}$ & $\boldsymbol{P}$ Value \\
\hline Neck size $(\mathrm{mm})$ & $3.1 \pm 1.3$ & $3.2 \pm 1.2$ & .783 \\
Aneurysm size $(\mathrm{mm})$ & $4.3 \pm 2.2$ & $5.3 \pm 2.0$ & .009 \\
Vessel diameter $(\mathrm{mm})$ & $2.5^{\circ} \pm 0.6$ & $2.4 \pm 0.6$ & .687 \\
$\theta_{\mathrm{F}}$ & $1214^{\circ} \pm 32.7^{\circ}$ & $130.8^{\circ} \pm 33.6^{\circ}$ & .104 \\
$\theta_{\mathrm{P}}$ & $107.6^{\circ} \pm 26.6^{\circ}$ & $100.9^{\circ} \pm 27.1^{\circ}$ & .159 \\
AR & $1.3 \pm 0.5$ & $1.7 \pm 0.6$ & $<.001$ \\
SR & $1.7 \pm 1.2$ & $2.1 \pm 0.9$ & .029 \\
NPR & $1.4 \pm 0.7$ & $1.4 \pm 0.6$ & .805 \\
Area ratio & $2.0 \pm 2.0$ & $2.9 \pm 1.9$ & .011 \\
\hline
\end{tabular}

Note:- $\theta_{\mathrm{F}}$ indicates flow angle; $\theta_{\mathrm{P}}$, parent-daughter angle; NPR, neck-to-parent artery ratio.

when the value of (sensitivity + specificity-1) reaches its maximum. Conditional univariable logistic regression analysis was performed to calculate odds ratios of each geometric and morphologic parameter between the 2 groups, and adjusted ORs were taken into the calculation to adjust for aneurysm size, which is an established and strong predictor of aneurysm rupture. ${ }^{9,10,14}$ A $P$ value $\leq .05$ was regarded as statistically significant, and all tests were 2 -sided.

\section{RESULTS}

\section{General Demographics}

Among 2361 patients with 2674 aneurysms, 269 (11.4\%) had multiple aneurysms and $84(3.6 \%)$ had symmetric bilateral aneurysms. Of the 84 patients in the clinical trial, 21 were excluded for the following reasons: 1) inability to identify the location of the ruptured aneurysm based on the pattern of hemorrhage or neurosurgical findings $(n=9) ; 2)$ insufficient CT angiography quality $(n=3)$; 3$)$ the presence of fusiform, mycotic, or dissecting aneurysms $(n=5)$; and 4$)$ aneurysm related to an arteriovenous malformation $(n=4)$. Thus, 63 patients with 126 intracranial aneurysms were enrolled in this cohort. There were $15(23.8 \%)$ men and $48(76.2 \%)$ women, and their mean age was $62.5 \pm 9.8$ years. The most frequent location for the 126 intracranial aneurysms was at the posterior communicating artery $(n=68)$, followed by the middle cerebral artery $(n=34)$, the internal carotid artery $(n=20)$, the anterior cerebral artery $(n=2)$, and the vertebral artery $(n=2)$.

Aneurysm size, AR, SR, and area ratio in the ruptured group were significantly different from those of the unruptured group $(P<.05$, Table 1$)$, while neck size, vessel diameter, inflow angle, parent-daughter angle, and neck-to-parent artery ratio were not $(P>.05)$. For further analysis, the cutoff value was calculated by the receiver operating characteristic (Fig 2). The areas under the curve for aneurysm size, AR, SR, and area ratio were 0.667 (95\% CI, $0.571-0.762$ ) sensitivity of $69.8 \%$, specificity of $63.5 \% ; 0.703$ (0.612-0.794), sensitivity of $52.4 \%$, specificity of $85.7 \%$; 0.679 (0.585-0.773), sensitivity of $65.1 \%$, specificity of $57.1 \%$; and $0.695(0.603-0.787)$, sensitivity of $80.0 \%$, specificity of $48.6 \%$, respectively. The cutoff values of these geometric indices were 4.6 , $1.6,1.7$, and 1.5 , respectively.

Conditional logistic regression analysis of morphologic and geometric parameters between the 2 groups is given in Table 2. An aneurysm size of $\geq 4.6 \mathrm{~mm}$ showed strong association with rupture (OR, 3.625; 95\% CI, 1.657-7.929). After adjustment for aneurysm size, an AR of $\geq 1.6$ (adjusted OR, 9.521;95\% CI, 2.182-41.535), area

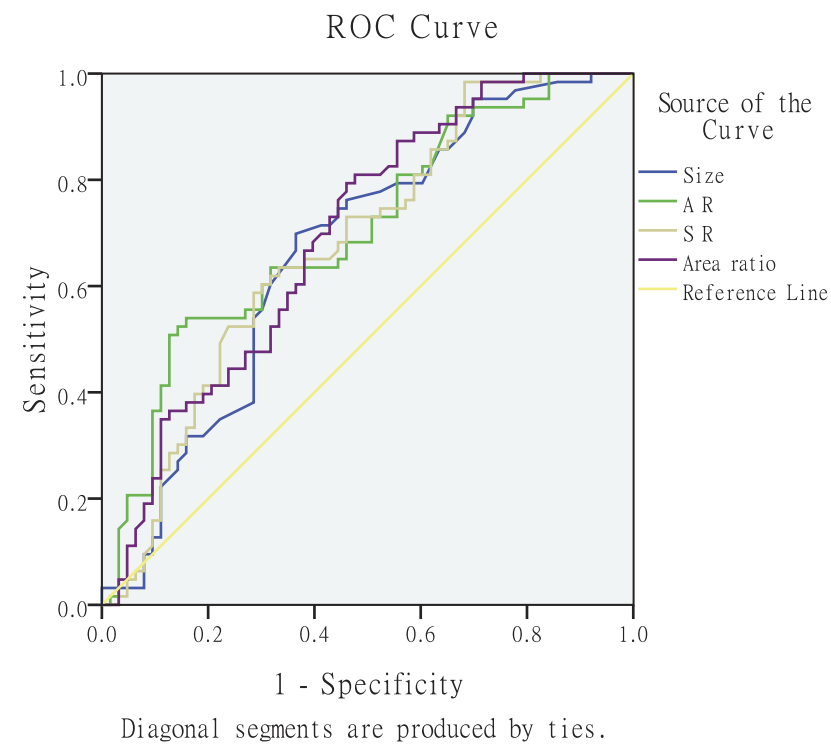

FIG 2. Graph depicting the receiver operating characteristic curves for aneurysm size, AR, SR, and area ratio in the symmetric bilateral aneurysm. The areas under the curve for aneurysm size, AR, SR, and area ratio are the following: 0.667 (95\% Cl, 0.571-0.762), 0.703 (95\% Cl, 0.612-0.794), 0.679 ( $95 \% \mathrm{Cl}, 0.585-0.773)$, and $0.695(95 \% \mathrm{Cl}, 0.603-0.787)$, respectively. The receiver operating characteristic area for $\operatorname{AR~}(0.703 ; 95 \% \mathrm{Cl}, 0.612-0.794$; $P<.001)$ tends to be larger than the area under the curve of the other parameters. AR had the highest area under the curve.

ratio of $\geq 1.5$ (adjusted OR, 4.089; 95\% CI, 1.247-13.406), and irregular wall (adjusted OR, 10.443; 95\% CI, 3.394-32.135) were significantly associated with aneurysm rupture, but not SR.

\section{DISCUSSION}

Unruptured intracranial aneurysms are common lesions, and aneurysm rupture can be catastrophic. ${ }^{2,3,10,12,14}$ Not all unruptured intracranial aneurysms will rupture, and the management of unruptured intracranial aneurysms remains controversial in neurosurgery. Reliable, simple-to-use predictors of higher rupture risk to aid in treatment decisions for unruptured intracranial aneurysms are not available. In previous studies, the decision-making process was based mainly on size, with the risk of rupture considered significantly increased for aneurysms of $\geq 7 \mathrm{~mm}) .{ }^{10,14,15}$ However, various authors have shown that a large proportion of ruptured aneurysms are, in fact, $<7 \mathrm{~mm} .{ }^{16-18}$ Our study indicates that the mean size of ruptured aneurysms is $5.29 \mathrm{~mm}$ (range, $2.0-11.3 \mathrm{~mm}$ ). More often than not, the ruptured aneurysm is not the largest aneurysm. Factors beyond size may be more important in determining the actual rupture risk.

\section{Irregular Wall and AR of Symmetric Bilateral Aneurysms Predict Rupture}

Previous retrospective studies found that aneurysm wall irregularity is associated with increased risk of rupture, but they were not adjusted for aneurysm size. ${ }^{19-21}$ Recently, a large-cohort prospective study found that unruptured aneurysms with a daughter $\mathrm{sac}$ (an irregular protrusion of the wall of the aneurysm) are more likely to rupture than aneurysms with a regular shape. ${ }^{14}$ Our study shows that after adjustment for aneurysm size, AR and irregular shape are associated with aneurysm rupture. Previous studies on AR indicated conflicting results, finding a significant 


\begin{tabular}{|c|c|c|c|c|c|c|}
\hline & \multicolumn{2}{|c|}{$\begin{array}{c}\text { Ruptured } \\
(n=63) \\
\end{array}$} & \multicolumn{2}{|c|}{$\begin{array}{c}\text { Unruptured } \\
(n=63)\end{array}$} & \multirow[b]{2}{*}{ OR $(95 \% \mathrm{CI})$} & \multirow[b]{2}{*}{ AOR (95\% Cl) } \\
\hline & No. & $\%$ & No. & $\%$ & & \\
\hline $\begin{array}{l}\text { Aneurysm size } \\
\geq 4.6 \mathrm{~mm}\end{array}$ & 44 & 69.8 & 23 & 36.5 & 3.625 (1.657-7.929) & - \\
\hline AR & & & & & & \\
\hline $\mathrm{SR}^{\geq 1.6}$ & 33 & 52.4 & 9 & 14.3 & 13.000 (3.086-54.771) & $9.521(2.182-41.535)$ \\
\hline $\begin{array}{l}\quad \geq 1.7 \\
\text { Area ratio }\end{array}$ & 41 & 65.1 & 27 & 39.0 & $2.556(1.183-5.523)$ & $0.970(0.320-2.945)$ \\
\hline $\begin{array}{l}\geq 1.5 \\
\text { Aneurysm wall }\end{array}$ & 51 & 80.9 & 30 & 47.6 & $6.250(2.175-17.958)$ & 4.089 (1.247-13.406) \\
\hline $\begin{array}{l}\text { Irregular wall } \\
\text { Aneurysm shape }\end{array}$ & 50 & 79.4 & 15 & 23.8 & $8.000(3.157-20.270)$ & $10.443(3.394-32.135)$ \\
\hline $\begin{array}{l}\text { Spheric } \\
\text { Flow angles }\end{array}$ & 31 & 49.2 & 34 & 53.9 & $0.833(0.420-1.653)$ & $1.078(0.499-2.330)$ \\
\hline Equivalent flow & 6 & 9.5 & 11 & 17.5 & Reference & Reference \\
\hline Straight flow & 43 & 68.3 & 35 & 55.6 & 2.175 (0.728-6.497) & $1.749(0.505-6.057)$ \\
\hline Curved flow & 14 & 22.2 & 17 & 27.0 & $1.457(0.405-5.243)$ & $2.054(0.491-8.589)$ \\
\hline
\end{tabular}

Note:-AOR indicates adjusted odds ratios.

difference between the ruptured and unruptured groups, proving that $\mathrm{AR}$ is a relevant predictor in estimating the aneurysm rupture risk. ${ }^{6,19,22-31}$ The conflicting results can be explained by the lack of adjustment for patient-specific risk factors for aneurysm rupture and by the use of different imaging techniques and measurement methodology. ${ }^{22,27}$ Regarding AR, only 3 previous studies aimed to minimize the confounding factors by studying patients with multiple intracranial aneurysms. Two studies found that the AR of intracranial aneurysms correlates with aneurysm rupture, but the authors did not adjust for aneurysm size in the multivariable analysis. ${ }^{25,31}$ Our study is similar to a prior one that found that AR is associated with aneurysm rupture after adjusting for aneurysm size and location. ${ }^{22}$ Additionally, the critical AR for rupture has varied among previous studies, with AR cutoff values ranging from 1.3 to 1.8 , and remains controversial. ${ }^{6,19,22,23,26}$ In our study, an AR of $\geq 1.6$ was significantly associated with aneurysm rupture.

Previous studies on flow angle, parent-daughter angle, aneurysm width, and neck width have shown conflicting results, with insignificant or marginally significant $P$ values for aneurysm rupture. ${ }^{5,13,16,31-33}$ The conflicting results may be ascribed to limited follow-up data and differences in imaging techniques and measurement methodology. The area ratio takes into account the aneurysm itself (maximal perpendicular height and aneurysm width) and the local vessel (Dv and neck width). Our study shows that the area ratio is associated with aneurysm rupture after adjusting for aneurysm size. More than $80 \%$ of all ruptured aneurysms had an area ratio of $>1.5$ (the optimal threshold distinguishing the ruptured from unruptured intracranial aneurysms), whereas $52.38 \%$ of all unruptured intracranial aneurysms had an area ratio less than the cutoff value. More important, the area ratio in the ruptured group $(2.9 \pm 1.9)$ is larger than that of the unruptured group $(2.0 \pm 2.0)(P=.011)$.

It has previously been shown that as the intracranial aneurysm enlarges, the blood flow velocity becomes slower within the intracranial aneurysm, reducing the wall shear stress and making the intracranial aneurysm prone to rupture. ${ }^{7,30,34-38}$ From the perspective of hemodynamics, aneurysm area is proportional to the volume of blood contained by the aneurysm per unit of time, and the area of the parent artery in the neck is proportional to the aneurysm blood flow per unit of time provided by the parent artery via the aneurysm neck. Equal $\mathrm{A}_{2}$ values but higher $A_{1}$ values indicate a greater blood volume contained by the aneurysm per unit of time but slower blood flow velocity and lower mean wall shear stress in the aneurysm, making the risk of aneurysm rupture higher. As for conditions involving the same $A_{1}$ values but lower $\mathrm{A}_{2}$ values, the parent artery provides a reduced volume of blood to the aneurysm via the aneurysm neck, resulting in a slower velocity of blood flow and lower mean wall shear stress in the aneurysm, which also cause a higher rupture risk.

\section{Limitations}

One should consider some limitations inherent to this study: This is a retrospective analysis, which could cause biased selection of patients who underwent CT angiography. We used CT angiography data in the research and did not compare results with catheter digital subtraction angiography, which traditionally has been considered the criterion standard for aneurysm detection. However, CT angiography has high sensitivity and specificity for the detection of intracranial aneurysms and good consistency. ${ }^{11,12,22,39}$ Hence, we believe that the chances of misdiagnosis of intracranial aneurysms by CT angiography should be acceptably small. Another limitation of is that the area ratio is a weak predictor with marginally significant odds ratios for aneurysm rupture, even after adjustment for aneurysm size, so a correlation analysis between the area ratio and hemodynamics is needed. Finally, aneurysm size, irregular shape, and area ratio might be a consequence rather than the cause of aneurysm rupture; therefore, a prospective study, involving a geometric model comparison of aneurysms before and after rupture, is necessary.

\section{CONCLUSIONS}

We compared the aneurysm characteristics of ruptured and unruptured aneurysms in the same patient, by using CT angiography images according to a standard measurement protocol. AR, irregular shape, and area ratio are independent risk factors for aneurysm rupture. Those aneurysm characteristics alone in the current study can be helpful in distinguishing the ruptured symmetric bilateral intracranial aneurysms from unruptured ones.

\section{ACKNOWLEDGMENT}

The authors thank Dr Jian-Jun Zhan (Shantou University Medical College, Shantou, China) for his assistance with the statistical analysis of the data during the preparation of this article.

\section{REFERENCES}

1. Vlak MH, Algra A, Brandenburg R, et al. Prevalence of unruptured intracranial aneurysms, with emphasis on sex, age, comorbidity, 
country, and time period: a systematic review and meta-analysis. Lancet Neurol 2011;10:626-36 CrossRef Medline

2. Li MH, Chen SW, Li YD, et al. Prevalence of unruptured cerebral aneurysms in Chinese adults aged 35 to 75 years: a cross-sectional study. Ann Intern Med 2013;159:514-21 CrossRef Medline

3. Van Gijn J, Kerr RS, Rinkel GJ. Subarachnoid haemorrhage. Lancet 2007;369:306-18 CrossRef Medline

4. Ingall T, Asplund $\mathrm{K}$, Mähönen $\mathrm{M}$, et al. A multinational comparison of subarachnoid hemorrhage epidemiology in the WHO MONICA stroke study. Stroke 2000;31:1054-61 CrossRef Medline

5. Baharoglu MI, Schirmer CM, Hoit DA, et al. Aneurysm inflow-angle as a discriminant for rupture in sidewall cerebral aneurysms: morphometric and computational fluid dynamic analysis. Stroke 2010; 41:1423-30 CrossRef Medline

6. Dhar S, Tremmel M, Mocco J, et al. Morphology parameters for intracranial aneurysm rupture risk assessment. Neurosurgery 2008; 63:185-96; discussion 196-97 CrossRef Medline

7. Tremmel M, Dhar S, Levy EI, et al. Influence of intracranial aneurysm-to-parent vessel size ratio on hemodynamics and implication for rupture: results from a virtual experimental study. Neurosurgery 2009;64: 622-30; discussion 630-31 CrossRef Medline

8. Jeon JS, Ahn JH, Huh W, et al. A retrospective analysis on the natural history of incidental small paraclinoid unruptured aneurysm. J Neurol Neurosurg Psychiatry 2014;85:289-94 CrossRef Medline

9. Greving JP, Wermer MJ, Brown RD JR, et al. Development of the PHASES score for prediction of risk of rupture of intracranial aneurysms: a pooled analysis of six prospective cohort studies. Lancet Neurol 2014;13:59-66 CrossRef Medline

10. Wiebers DO, Whisnant JP, Huston J III, et al; International Study of Unruptured Intracranial Aneurysms Investigators. Unruptured intracranial aneurysms: natural history, clinical outcome, and risks of surgical and endovascular treatment. Lancet 2003;362:103-10 CrossRef Medline

11. Lubicz B, Levivier M, François O, et al. Sixty-four-row multisection $\mathrm{CT}$ angiography for detection and evaluation of ruptured intracranial aneurysms: interobserver and intertechnique reproducibility. AJNR Am J Neuroradiol 2007;28:1949-55 CrossRef Medline

12. Forbes G, Fox AJ, Huston J 3rd, et al. Interobserver variability in angiographic measurement and morphologic characterization of intracranial aneurysms: a report from the International Study of Unruptured Intracranial Aneurysms. AJNR Am J Neuroradiol 1996; 17:1407-15 Medline

13. Lin N, Ho A, Gross BA, et al. Differences in simple morphological variables in ruptured and unruptured middle cerebral artery aneurysms. J Neurosurg 2012;117:913-19 CrossRef Medline

14. Morita A, Kirino T, Hashi K, et al; UCAS Japan Investigators. The natural course of unruptured cerebral aneurysms in a Japanese cohort. N Engl J Med 2012;366:2474-82 CrossRef Medline

15. International Study of Unruptured Intracranial Aneurysms Investigators. Unruptured intracranial aneurysms: risk of rupture and risks of surgical intervention. NEngl J Med 1998;339:1725-33 CrossRef Medline

16. Baharoglu MI, Lauric A, Gao BL, et al. Identification of a dichotomy in morphological predictors of rupture status between sidewalland bifurcation-type intracranial aneurysms. J Neurosurg 2012;116: 871-81 CrossRef Medline

17. Flores BC, Scott WW, Eddleman CS, et al. The A1-A2 diameter ratio may influence formation and rupture potential of anterior communicating artery aneurysms. Neurosurgery 2013;73:845-53; discussion 852-53 CrossRef Medline

18. Rahman M, Ogilvy CS, Zipfel GJ, et al. Unruptured cerebral aneurysms do not shrink when they rupture: multicenter collaborative aneurysm study group. Neurosurgery 2011;68:155-60; discussion 160-61 CrossRef Medline

19. Beck J, Rohde S, el Beltagy M, et al. Difference in configuration of ruptured and unruptured intracranial aneurysms determined by biplanar digital subtraction angiography. Acta Neurochir (Wien) 2003;145:861-65; discussion 865 CrossRef Medline
20. de Rooij NK, Velthuis BK, Algra A, et al. Configuration of the circle of Willis, direction of flow, and shape of the aneurysm as risk factors for rupture of intracranial aneurysms. J Neurol 2009;256:45-50 CrossRef Medline

21. Rohde S, Lahmann K, Beck J, et al. Fourier analysis of intracranial aneurysms: towards an objective and quantitative evaluation of the shape of aneurysms. Neuroradiology 2005;47:121-26 Medline

22. Backes D, Vergouwen MD, Velthuis BK, et al. Difference in aneurysm characteristics between ruptured and unruptured aneurysms in patients with multiple intracranial aneurysms. Stroke 2014;45: 1299-303 CrossRef Medline

23. Amenta PS, Yadla S, Campbell PG, et al. Analysis of nonmodifiable risk factors for intracranial aneurysm rupture in a large, retrospective cohort. Neurosurgery 2012;70:693-99; discussion 699-701 CrossRef Medline

24. Ujiie $\mathrm{H}$, Tamano $\mathrm{Y}$, Sasaki $\mathrm{K}$, et al. Is the aspect ratio a reliable index for predicting the rupture of a saccular aneurysm? Neurosurgery 2001;48:495-502; discussion 502-03 CrossRef Medline

25. Nader-Sepahi A, Casimiro $M$, Sen J, et al. Is aspect ratio a reliable predictor of intracranial aneurysm rupture? Neurosurgery 2004;54: 1343-47; discussion 1347-48 CrossRef Medline

26. Weir B, Amidei C, Kongable G, et al. The aspect ratio (dome/neck) of ruptured and unruptured aneurysms. J Neurosurg 2003;99:447-51 CrossRef Medline

27. Lauric A, Baharoglu MI, Malek AM. Ruptured status discrimination performance of aspect ratio, height/width, and bottleneck factor is highly dependent on aneurysm sizing methodology. Neurosurgery 2012;71:38-45 CrossRef Medline

28. Ryu CW, Kwon OK, Koh JS, et al. Analysis of aneurysm rupture in relation to the geometric indices: aspect ratio, volume, and volumeto-neck ratio. Neuroradiology 2011;53:883-89 CrossRef Medline

29. Sadatomo T, Yuki K, Migita K, et al. Morphological differences between ruptured and unruptured cases in middle cerebral artery aneurysms. Neurosurgery 2008;62:602-09; discussion 602-09 CrossRef Medline

30. Xiang J, Natarajan SK, Tremmel M, et al. Hemodynamic-morphologic discriminants for intracranial aneurysm rupture. Stroke 2011; 42:144-52 CrossRef Medline

31. Hoh BL, Sistrom CL, Firment CS, et al. Bottleneck factor and heightwidth ratio: association with ruptured aneurysms in patients with multiple cerebral aneurysms. Neurosurgery 2007;61:716-22 CrossRef Medline

32. You SH, Kong DS, Kim JS, et al. Characteristic features of unruptured intracranial aneurysms: predictive risk factors for aneurysm rupture. J Neurol Neurosurg Psychiatry 2010;81:479-84 CrossRef Medline

33. Jiang $Y$, Lan $Q$, Wang $Q$, et al. Correlation between the rupture risk and 3D geometric parameters of saccular intracranial aneurysms. Cell Biochem Biophys 2014;70:1417-20 CrossRef Medline

34. Takao H, Murayama Y, Otsuka S, et al. Hemodynamic differences between unruptured and ruptured intracranial aneurysms during observation. Stroke 2012;43:1436-39 CrossRef Medline

35. Tateshima S, Chien A, Sayre J, et al. The effect of aneurysm geometry on the intra-aneurysmal flow condition. Neuroradiology 2010;52: 1135-41 CrossRef Medline

36. Lauric A, Hippelheuser J, Cohen AD, et al. Wall shear stress association with rupture status in volume matched sidewall aneurysms. J Neurointerv Surg 2014;6:466-73 CrossRef Medline

37. Goubergrits L, Schaller J, Kertzscher U, et al. Statistical wall shear stress maps of ruptured and unruptured middle cerebral artery aneurysms. J R Soc Interface 2012;9:677-88 CrossRef Medline

38. Jou LD, Lee DH, Morsi $\mathrm{H}$, et al. Wall shear stress on ruptured and unruptured intracranial aneurysms at the internal carotid artery. AJNR Am J Neuroradiol. 2008;29:1761-67 CrossRef Medline

39. McKinney AM, Palmer CS, Truwit CL, et al. Detection of aneurysms by 64-section multidetector CT angiography in patients acutely suspected of having an intracranial aneurysm and comparison with digital subtraction and 3D rotational angiography. AJNR Am J Neuroradiol 2008;29:594-602 CrossRef Medline 